\title{
The development of instructional materials for reading literacy using the WISE approach
}

\author{
E.T. Priyatni*, A.R. As'ari, Nurchasanah \& Suharyadi \\ Universitas Negeri Malang, Malang, Indonesia
}

\begin{abstract}
This study aimed to develop instructional materials for reading literacy using the WISE approach. WISE stands for wondering, investigating, synthesizing, and expressing. The development of the instructional materials followed ADDIE stages (analysis, design, development, implementation and evaluation). The development of materials for reading literacy using the WISE approach consists of seven chapters: introduction, WISE principles, activities to promote the wondering skill, activities to promote the investigating habit, activities to promote the synthesizing skill, activities to promote the expressing skill and follow-up activities. The formation of the WISE technique in students is possible if wondering is encouraged in students. Students also need to stimulate curiosity by themselves to develop and implement an investigation design, analyze the investigation results and use creativity to synthesize and express ideas.
\end{abstract}

Keywords: instructional materials, reading literacy, wondering, investigating, synthesizing, and expressing

\section{INTRODUCTION}

One of the primary concerns of education in Indonesia is students' poor literacy. The result of PISA in 2018 showed a decrease in Indonesian student literacy scores compared to the 2015 PISA result (OECD 2019). The data further revealed that Indonesian students scored 371 in reading, 379 in mathematics and 396 in science. A significant decrease was also observed in the students' reading literacy score (OECD 2019). There was not a single Indonesian student who was able to achieve a level-5 reading literacy score. In fact, only $0.4 \%$ of the students were able to perform level-4 literacy skills, while the rest scored between levels 1-3 in terms of reading literacy. The students' low interest in reading was also proven by 2012 UNESCO statistical data, suggesting only $1(0.1 \%)$ out of 1000 people in Indonesia have a good reading interest (OECD 2014). Improving the quality of reading literacy in Indonesia is an important task in national education (Priyatni \& Nurhadi 2017).

The low reading literacy is not proportional to the abundance of information that students can access every day through technology. This information comes in the form of texts, images, tables, audio, and audio-visual components. The abundance of information that is present through technology is irreversible. Every minute, students can read articles or statuses posted on social media. Not all information is true and accurate. Therefore, students need to develop high literacy skills to filter, select and sort information and hoaxes. Literacy is the heart of human life and must be mastered and reached by everyone (Narey 2017). Everyone must be literate. Everyone must have basic literacy, including reading literacy.

The notion of literacy continues to develop, along with the development of digital technology. In the beginning, literacy was used to describe people's ability to decode and encode texts (Gurak 2001). However, since the mid-20th century, the concept of literacy has changed to literacy that

\footnotetext{
*Corresponding author: endah.tri.fs@um.ac.id
} 
focuses primarily on reading and writing, the two skills which form the basis for literacy in various matters (Kalantzis \& Cope 2015). Literacy also includes reading, writing, and numerical literacy, which constitute three basic life skills (Kalantzis \& Cope 2015). In the next development stage, literacy is defined as knowledge literacy, an understanding of something (knowledge). Furthermore, literacy is defined as the ability to think critically-creatively, which is supported by the tradition of reading-writing-numerical literacy and figures (pictures/tables) literacy. Both thinking activities have a different focus: critical reading is focused on assessing, while creative reading is focused on the process of making or producing (Paul \& Elder 2008; Priyatni \& Martutik 2020). This is in line with the 2015 PISA, which defines reading literacy as the ability to understand, apply, evaluate and reflect on texts to achieve goals, expand knowledge, and participate actively in social life (Csapó \& Funke 2017; OECD 2019).

Research on reading literacy has been carried out in various contexts in the world, including in Indonesia. Wu and Peng (2017) examined the effect of modality on students' reading literacy. They found that students had better reading literacy through printed reading materials. Another study by Tan (2015) showed that the existence of Wikis, email, blogs and other online reading sources could improve students' reading literacy. Previous research carried out by Boyle et al. (2019) suggested that reading literacy is also important for students with special needs. The School Literacy Movement (SLM) carried out in schools in Indonesia can increase student interest in reading and reading activity frequency (Sutrisna et al. 2019). The results of the preliminary study indicate that the School Literacy Movement program has not been able to make students literate in reading nor build students' ability to reason. To increase the role of SLM in promoting reading literacy, research and development of a WISE-oriented integrative reading literacy prototype was carried out simultaneously.

WISE stands for Wondering, Investigating, Synthesizing and Expressing. WISE is not a learning model; WISE is a goal. By carrying out WISE-oriented learning, students will have: (1) a good wondering habit, that is, asking a lot of questions and always wanting to know more, (2) strong investigating skills, which means being willing and able to find the necessary information, (3) solid synthesizing skills, namely being able to link and draw conclusions, and (4) increased engagement due to having a purpose and being skilled in communicating ideas or findings.

\section{METHODS}

This study employed a Research and Development (R \& D) method to develop a product. The product developed in this study was the prototype of WISE-oriented instructional materials for reading literacy. The development of the prototype followed the stages of ADDIE (analysis, design, development, implementation, and evaluation (Spector et al. 2014). The analysis of the initial conditions and the requirements needed for developing the prototype was conducted at the Analysis stage. This stage was followed by designing and developing the prototype. Then, learning and materials experts, as well as practitioners (teachers), were invited to examine the validity of the prototype. Inputs from the experts and the practitioners were used to revise the product. The revised product was implemented in the classroom, and the implementation of the product was observed, evaluated, and reviewed.

This article focuses on describing the process of developing the prototype and the results of expert validation rather than elaborating on the implementation of the product to potential users/students. The data of this study was collected in the form of comments, critiques, suggestions, and judgments from the experts and practitioners team. The learning and material experts hold doctoral degrees and have more than ten years of teaching experience. The practitioners involved for expert validation were the teachers from SMPN 1 Tana Tidung Regency in North Kalimantan. The researchers in this study acted as the key instruments in data collection, data analysis, and data interpretation assisted by an instrument called product review guidelines. Data analysis was focused on analyzing data from the experts/practitioners involved in expert validation. The results of this analysis were then used to improve the product. 


\section{RESULTS AND DISCUSSION}

The products developed in this study were reading literacy instructional materials with WISE orientation. WISE is not a learning model but a goal. It means that when these learning materials are used in learning, students' wondering, investigating, synthesizing, and expressing skills can be promoted.

The prototype of the materials consists of seven chapters: (1) introduction, (2) WISE principles, (3) activities to promote the "wondering" skill, (4) activities to promote the "investigating" habit, (5) activities to promote the "synthesizing" skill, (6) activities to promote the "expressing" skill and (7) follow-up activities. The introduction section presents the context, focus and method of the study. In Chapter 2, the nature or the essence of WISE is presented, including the definition, purpose, and elements of WISE. Chapters 3, 4, 5 and 6 contain activities to cultivate wondering, investigating, synthesizing, and expressing skills, respectively, which are described below.

In detail, the activities to promote Wondering section present a multimodal text stimulus, which can be in the form of images, tables, infographics, diagrams, or continuous texts (in the form of sentences). The stimulus chosen is attractive and has the elements of novelty and local wisdom to arouse students' curiosity. From this stimulus, students are asked to ask questions. The next section is concerned with activities to promote the investigation habit. The main aim of an investigation activity is to investigate the major ideas found in the activity of wondering through the research process based on facts and by recording the results of the investigation accurately. The investigation process includes three activities, namely, planning, implementing, and processing. Activities at the planning stage include selecting which questions will be followed up (answered or investigated), finding out what information should be collected, where the information sources are, how the information is obtained, what tools/instruments are needed to gather the information. At the implementation stage, the activities carried out by students include interviewing, conducting surveys, surfing in cyberspace, and conducting safe experiments. At the processing stage, the activities carried out by students are assessing the validity of the data, storing the data safely, compiling the data regularly, and presenting the data properly.

The investigation process includes three activities: planning, implementing, and processing. Activities at the planning stage include selecting which questions will be followed up (answered or investigated), finding out what information should be collected, where the information sources are, how the information is obtained, what tools/instruments are needed to gather the information. At the implementation stage, the activities carried out by students include: interviewing, conducting surveys, surfing in cyberspace, and conducting safe experiments. At the processing stage, the activities carried out by students are assessing the validity of the data, storing the data safely, compiling the data regularly, and presenting the data properly.

Synthesizing activities primarily aim to synthesize big ideas developed through investigation, link the data/information obtained from the investigation and determine the relationship between the ideas. Activities undertaken by students to hone their synthesizing skill include checking the validity of the data sources, checking the quality and credibility of the data sources, comparing the data sources with other data sources, checking whether there are contradictory data sources, linking the data with other data, drawing conclusions and compiling findings.

The main purpose of expressing activities is to communicate big ideas that have been developed, communicate new ideas, use an appropriate format, communicate new ideas that have been developed clearly and creatively, and communicate new ideas using various modes and technologies. Expressions must be thought through, and they must not be careless. Students are encouraged to present new ideas that have been found in the form of videos, audios, infographics, full texts that contain tables, diagrams, etc.

The product prototype was validated by two learning material experts and two learning experts. The researchers presented the developed product via virtual meeting, and then the experts were asked to provide comments on the product. The summary of the results of the expert's analysis can be seen in Table 1. 
Table 1. The expert validation results.

\begin{tabular}{|c|c|c|}
\hline No. & Analyzed Aspects & Analysis Results \\
\hline 1. & $\begin{array}{l}\text { Stimulus to stimulate the devel- } \\
\text { opment of wondering skill }\end{array}$ & $\begin{array}{l}\text { Mostly, the stimulus is provided in the form of images and } \\
\text { infographics. The variation of stimulus can be full story } \\
\text { texts, videos or audio. }\end{array}$ \\
\hline 2. & $\begin{array}{l}\text { Activities to promote the won- } \\
\text { dering skill }\end{array}$ & $\begin{array}{l}\text { The question column is provided for students because ques- } \\
\text { tions should arise from students so that they have a more } \\
\text { positive impact. } \\
\text { If students have not asked wondering questions or questions } \\
\text { that arouse curiosity and require investigation, the teacher } \\
\text { can guide students by giving guiding questions. }\end{array}$ \\
\hline 3. & $\begin{array}{l}\text { Activities to promote the investi- } \\
\text { gation skill }\end{array}$ & $\begin{array}{l}\text { If there is more than one wondering question, let students } \\
\text { choose which question to answer through the investigation. } \\
\text { Generally, investigative activities have been provided by the } \\
\text { teacher. } \\
\text { Let students plan ways to investigate, carry out, and process } \\
\text { the results. } \\
\text { Investigations work best when students are left to figure out } \\
\text { how to investigate. } \\
\text { Let the students find a way to find answers to the selected } \\
\text { questions, to whom they should ask to find answers, what } \\
\text { questions to ask. }\end{array}$ \\
\hline 4. & $\begin{array}{l}\text { Activities to promote the synthe- } \\
\text { sizing skill }\end{array}$ & $\begin{array}{l}\text { Synthesizing information is not easy. Add examples of find- } \\
\text { ing data - then invite students to classify, determine which } \\
\text { one is better, or make conclusions. } \\
\text { Provide a column that guides students to collect facts, then } \\
\text { ask students to validate which one is the best, which one is } \\
\text { chosen for what. }\end{array}$ \\
\hline 5. & $\begin{array}{l}\text { Activities to promote the } \\
\text { expressing skill }\end{array}$ & $\begin{array}{l}\text { The most important thing in expressing activities is that } \\
\text { students can communicate their ideas creatively. } \\
\text { Students can organize their ideas attractively by using vari- } \\
\text { ous modes (oral writing, audio, audio-visual, infographics, } \\
\text { graphics, tables, etc.). }\end{array}$ \\
\hline
\end{tabular}

The practitioners (teachers) invited also provided suggestions on the product developed in this study. The teachers' suggestions can be seen in Table 2 .

Based on the input from material experts, learning experts and practitioners (teachers), the product was revised from the aspect of the stimulus which is used to foster students' wondering skill by adding various stimuli, which are familiar to the students, and exploring local wisdom in the area where the students live. This is in line with the direction of reading literacy, where the focus of the study is text (OECD 2018), and text is a meaningful message (Anderson \& Anderson 2003) and is multimodal (Kalantzis \& Cope 2015). Literacy in the modern era must be directed to understand multiliteracies, namely multi-contextual and multimodal texts (Kalantzis \& Cope 2015). Multi-contextual texts include texts relating to community setting, social role, interpersonal relations, identity and subject matter, while the multimodal scope includes written, visual, spatial, tactile, gestural, audio, and oral (Kalantzis \& Cope 2015).

Suggestions for incorporating local cultural values into WISE-oriented reading literacy are also used as a reference for revising the product. This is in line with the policy of strengthening character education stated in the 2013 curriculum and contained in the Merdeka Belajar curriculum's grand design. Local wisdom is the basic asset given to students to familiarize them with existing noble values, either as individuals, communities, or citizens. Local culture has high moral values that can be used as a source to strengthen student character. Character is a set of moral beliefs or personality which is formed from the internalization of various virtues that are believed and used as a basis for shaping a point of view, thinking, behaving and acting (Stevenson 2006). Character education 
Table 2. Suggestions from the practitioners.

\begin{tabular}{|c|c|c|}
\hline No. & Analyzed Aspects & Analysis Results \\
\hline 1. & $\begin{array}{l}\text { Stimulus to stimulate the devel- } \\
\text { opment of the wondering skill }\end{array}$ & $\begin{array}{l}\text { The stimulus should be familiar to the students. } \\
\text { The stimulus should take advantage of local wisdom so that } \\
\text { students can get to know the richness of culture, nature and } \\
\text { traditions that exist in the area. } \\
\text { The stimulus should be associated with the problems that } \\
\text { exist around the students so that they get used to solving } \\
\text { problems around them. } \\
\text { Stories can also be used as a stimulus, not necessarily in the } \\
\text { form of pictures. }\end{array}$ \\
\hline 2. & $\begin{array}{l}\text { Activities to promote the won- } \\
\text { dering skill }\end{array}$ & $\begin{array}{l}\text { Lead questions are needed so that students can answer } \\
\text { wondering questions. } \\
\text { Many examples are needed so that students can answer } \\
\text { wondering questions. } \\
\text { High-level questions should be added. }\end{array}$ \\
\hline 3. & $\begin{array}{l}\text { Activities to promote the investi- } \\
\text { gation skill }\end{array}$ & $\begin{array}{l}\text { How to find information, is also a form of investigation. } \\
\text { Investigations do not have to be experiments. }\end{array}$ \\
\hline 4. & $\begin{array}{l}\text { Activities to promote the synthe- } \\
\text { sizing skill }\end{array}$ & $\begin{array}{l}\text { Concrete examples are needed to practice the synthesizing } \\
\text { skill. }\end{array}$ \\
\hline 5. & $\begin{array}{l}\text { Activities to promote the } \\
\text { expressing skill }\end{array}$ & $\begin{array}{l}\text { There is an activity of giving feedback after students express } \\
\text { their work. } \\
\text { Feedback can come from netizens - by uploading student } \\
\text { work to Youtube. }\end{array}$ \\
\hline
\end{tabular}

needs to be continuously conducted, and sources of value for strengthening character should be taken from the nation's noble values and the Indonesian nation's culture. Character education aims to foster the younger generation's personality and form individuals who have good character and can serve as good citizens (Priyatni 2013).

The examples of wondering questions that stimulate critical thinking, creativity, collaboration and investigative communication skills should be added. This suggestion is very important and must be used as the "spirit" to develop WISE-based reading literacy instructional materials. Wondering is essentially an innate skill that waits for stimuli/triggers to grow and develop (L'Ecuyer 2014). Wondering skills must be cultivated from within students. Let the students take the initiative. The teacher is allowed to provide triggers at an early stage only, and then slowly, the teacher allows the curiosity to grow from within the student. This needs to be given special attention because the initiative that always comes from the teacher will numb the curiosity of the students (L'Ecuyer 2014). When wondering is not grown in students, there will be a mechanical process in learning, so that learning is only repetitive, becoming a routine that is deadly and alienating (L'Ecuyer 2014).

The focus of developing WISE-oriented instructional materials is promoting wondering, investigating, synthesizing, and expressing skills in students. These four goals ultimately lead to the growth of creative thinking skills. Creative thinking is one of the important goals of education (Wolska \& Dlugosz 2015). A key role in developing the creativity of students at all ages is played by formal education and teachers are responsible for stimulating students' creative abilities, forming student personality and attitudes that are conducive to creativity, and teaching students creative thinking skills and creative problem solving (Wolska \& Dlugosz 2015).

Communication is also an important skill that becomes the focus of developing WISE-oriented reading literacy instructional materials. Expressing requires students to be able to choose different patterns of expression according to the context (Kalantzis \& Cope 2015). Cope exemplifies that the way a doctor delivers news about laboratory results to patients will be different from that used when conveying it to the patient's parents (Kalantzis \& Cope 2015). Delivering the same message to people of different ages, different social status (student-teacher) requires different speech forms. Expressing is an important skill that allows communication to be established well, smoothly, without any emotional obstacles. 


\section{CONCLUSIONS}

The reading literacy product prototype with wondering, investigating, synthesizing, and expressing (WISE) was developed to promote student curiosity, investigative habits, synthesize skill and ability to communicate ideas appropriately and attractively. To develop the student wondering skill, the stimulus is presented in the form of multimodal texts, which can be in the form of images, tables, infographics, diagrams, or continuous texts (in the form of sentences). The stimulus chosen is an interesting, attractive stimulus and has novelty and local wisdom elements. This curiosity is continued by encouraging students to investigate in their own way. Investigative data is grouped, compared, synthesized and then communicated using various modes. WISE will be formed in students if curiosity is encouraged from within the student, meaning that the students develop curiosity by themselves, design, implement and process the results of investigations, as well as synthesize and express ideas using their creativity.

\section{ACKNOWLEDGEMENT}

We would like to thank the Institute for Research and Community Service, Universitas Negeri Malang, for funding this study with the 2020 PNBP grant (contract number: 4.3.590 '/UN32.14.1/LT/2020).

\section{REFERENCES}

Anderson, M., \& Anderson, K. 2003. Type Text in English. Macmillan.

Boyle, S. A., Boyle, D., \& Chapin, S. E. 2019. Effects of Shared Reading on the Early Language and Literacy Skills of Children with Autism Spectrum Disorders: A Systematic Review. Sage.

Gurak, L. J. 2001. Cyberliteracy: Navigating the Internet with Awareness. Yale University Press.

Kalantzis, M., \& Cope, B. 2015. Literacies. Cambridge University Press.

L'Ecuyer, C. 2014. The Wonder Approach to Learning. Hypothesis and Theory Article, 8(October), 1-8.

Narey, M. J. 2017. Multimodal Perspectives of Language, Literacy, and Learning in Early Childhood. The Creative and Critical "Art" of Making Meaning (12th ed.). Springer.

OECD. 2014. PISA 2012 Results: Creative Problem Solving: Students'Skills in Tackling Real-Life Problems: Vol. V. oecd publishing.

OECD. 2018. PISA 2018 Reading Literacy Framework.

OECD. 2019. PISA 2018 results (Volume I): What 15-year-old Student in Indonesia Know and Can Do. Indonesia-Country Note-PISA 2018 Result.

Paul, R., \& Elder, L. 2008. The Nature and Functions of Critical \& Creative Thinking. Nature, 2008, 1-52.

Priyatni, E. T. 2013. Internalisasi Karakter Percaya Diri dengan Teknik Scaffolding. Pendidikan Karakter, 3(2), 164-173.

Priyatni, E. T., \& Martutik, M. 2020 The Development of a Critical-Creative Reading Assessment Based on Problem Solving. Sage Open, 10(2), 1-9.

Priyatni, E. T., \& Nurhadi. 2017. Membaca Kritis dan Literasi Kritis (kesatu). TSmart.

Spector, M., Merrill, D., Elen, J., Bishop, M. J., \& Savelyeva, T. 2014. and Technology.

Stevenson, N. 2006. Young Person's Character Education Handbook (S. Pines (ed.)). JIST Publishing.

Sutrisna, I., Sriwulan, S., \& Nugraha, V. 2019. Pengaruh Gerakan Literasi dalam Meningkatkan Minat Baca Siswa. Parole (Jurnal Penddikan Bahasa Dan Sastra Indonesia), 2(4), 521-528. https://journal.ikipsiliwangi.ac.id/index.php/parole/article/view/2878

Tan, A. 2015. Creativity in the Twenty First Century Creativity, Culture. Springer.

Wolska, M., \& Dlugosz. 2015. Stimulating the Development of Creativity and Passion in Children and Teenagers in Family and School Environment - Inhibitors and Opportunities to Overcome Them. Procedia - Social and Behavioral Sciences, 174, 2905-2911.

Wu, J.Y., \& Peng, Y. C. 2017. The Modality Effect on Reading Literacy: Perspectives Students' Online Reading Habits, Cognitive and Metacognitive Strategies, and Web Navigation Skills Across Regions. Interactive Learning Environments, 25, 859-876. 